\title{
On the role of the exchange rate as a tool for industrial competitiveness
}

\author{
Sobre o papel da taxa de câmbio como \\ ferramenta de competitividade industrial
}

\author{
ARIEL DVOSKIN * \\ GERMÁN DAVID FELDMAN ${ }^{+}$ \\ GUIDO IANNI ${ }^{x},{ }^{x x}$
}

\begin{abstract}
RESUMO: Através de um modelo de dois setores negociáveis para uma economia aberta e de preços inspirada na tradição sraffiana clássica, que concebe o padrão do comércio como um problema de escolha técnica, examinamos algumas dificuldades com o recurso à taxa de câmbio política como ferramenta para promover a competitividade setorial. Para esse objetivo, distinguimos entre economias que produzem apenas manufaturados daquelas em que o setor mais lucrativo explora os recursos naturais em condições de aluguel diferenciado. Mostramos que, quando ambos os setores comercializáveis produzem bens industriais, a desvalorização convencional geralmente não permite que um setor doméstico atinja a competitividade internacional sem prejudicar o outro. embora quando o setor predominante opere sob condições de renda diferencial, mesmo que seja possível o desenvolvimento de um novo setor - definindo a taxa de câmbio no nível de "equilíbrio industrial” -, isso exige que o formulador de políticas determine o efeito das mudanças na taxa de câmbio, tanto em direção quanto em magnitude, nas demais variáveis distributivas.

PALAVRAS-CHAVE: Abordagem clássica de preços e aluguel diferencial de distribuição; política cambial; equilíbrio industrial; competitividade setorial.
\end{abstract}

\footnotetext{
* Consejo Nacional de Investigaciones Científicas y Técnicas del Instituto de Altos Estudios Sociales CONICET-IDAES, Universidad Nacional de San Martin - UNSAM, Buenos Aires, Argentina. E-mail: advoskin@unsam.edu.ar; ORCID: https://orcid.org/0000-0001-6603-6012.

+ Consejo Nacional de Investigaciones Científicas y Técnicas del Instituto de Altos Estudios Sociales CONICET-IDAES, Universidad Nacional de San Martin - UNSAM, Buenos Aires, Argentina. E-mail: gfeldman@unsam.edu.ar; ORCID: https://orcid.org/0000-0003-1334-0103.

x Università Roma Ter, Roma, Italy. E-mail: guido_ianni@yahoo.com; ORCID: https://orcid.org/00000002-0479-4130.

${ }^{x x}$ A preliminary version of this article was presented at the 4th Workshop on New-Developmentalism: New Theory and Policy for Developing Countries, São Paulo School of Economics, July 25-26, 2019 and at the 2nd Workshop on Demand-Led Growth, Structural Change and Income Distribution, Federal University of Rio de Janeiro (IE-UFRJ), July 17-18, 2019. We would like to thank the participants of both events for their comments and suggestions. We would also like to thank two anonymous referees for their helpful observations on. Submitted: 17/July/2019; Approved: 1/August/2019.
} 
ABSTRACT: By means of a two-tradable-sector model for an open, price-taking economy inspired by the Classical-Sraffian tradition, which conceives the pattern of trade as a technicalchoice problem, we examine some difficulties with the recourse to exchange-rate policy as a tool to promote sectorial competitiveness. To this aim, we distinguish among economies that only produce manufactures from those in which the most profitable sector exploits natural resources under conditions of differential rent. We show that, when both tradable sectors produce industrial goods, conventional devaluation does not generally allow one domestic sector to reach international competitiveness without damaging the other. While when the prevailing sector operates under conditions of differential rent, even though the development of a new sector - by setting the exchange rate at its "industrial-equilibrium" level - is possible, this requires that the policymaker determines the effect of changes in the exchange rate, both in direction and magnitude, on the other distributive variables.

KEYWORDS: Classical approach to prices and distribution; differential rent; exchange rate policy; industrial equilibrium; sectorial competitiveness.

JEL Cl;assification: B22; E11; F43.

\section{INTRODUCTION}

In the last decade we have witnessed the emergence of a growing literature that highlights the role of the real exchange rate (RER) as a key factor to accelerate economic growth in small open peripheral economies (see, among Latin American scholars, Frenkel and Ros, 2006; Bresser, 2008).

In previous contributions (Dvoskin and Feldman, 2018; Dvoskin et al., 2019), we have critically discussed some of the expansionary channels of devaluations addressed by this literature, known as New Structuralism or New Developmentalism, showing they lack the sufficient generality to become a truly robust explanation of the drivers of economic growth. Moreover, we have shown that this negative conclusion at a theoretical level is also supported by empirical evidence that corroborates that the alleged relation from RER to growth is not conclusive. As Tadeu Lima, an author who broadly speaking can be considered as a member of the NewDevelopmentalist school, has recently accepted, "empirical research provides very mixed conclusions regarding the effects of devaluation on growth" (Marquez Ribeiro et al., 2017, p. 3).

On the one hand, these results should not cause much surprise. After all, only within the neoclassical approach it is possible to postulate sufficiently general relations between prices and quantities, but at the high cost of having recourse to an unacceptable treatment of the factor capital as a single magnitude (cf., e.g., Garegnani, 1970; and more recently, Dvoskin and Petri, 2017).

On the other hand, this mixed empirical evidence invites us to further investigate the robustness of other transmission channels from the exchange rate to output growth at a more theoretical level, not examined in our previous works with the sufficient detail. In particular, we shall here examine additional difficulties with one mechanism that aims to promote structural change: the role of the exchange 
rate as a "light-switch". That is, the idea that a higher exchange rate may enrich the prevailing productive structure with the development of new industrial sectors - potentially more dynamic-, which were not profitable before (i.e., at a lower exchange rate). This is, for instance, what authors like Frenkel and Ros (2006, p. 635) mean when they argue that "A more depreciated RER [real exchange rate] [...] encourages tradable activities that were not profitable before".

To this aim, we have recourse to a two-tradable-sector model for a small (price taking) open economy with persistent unemployment inspired by the surplus approach revived with the work of Sraffa (1960), which conceives the pattern of specialization as a special case of a problem of technical choices (see Kurz and Salvadori (1995) for a general treatment of the issue and Steedman (1999) for an application to small open economies). A general result of the technical-choice problem (which has not been questioned, so far) is that, given the level of one distributive variable (either the real wage or the profit rate), the technique - in this case, the commodity or groups of commodities produced - which, thanks to the action of free competition, tends to be adopted in the economy, is the one that affords the highest level of the other (endogenous) distributive variable (respectively, the profit rate or the real wage).

The distinguishing feature of the approach adopted here is that income distribution is conceived as the outcome of a complex maze of political and institutional factors. This means that, depending on the specific institutional context under consideration, either the profit rate or the real wage can act as the "primum movens" - it can be exogenously given to the price system - while the remaining distributive variable must necessarily adjust to give consistency to the system (see Garegnani, 1984).

Relative to neoclassical theory, the advantages of the surplus approach are at least two: first, it is compatible with persistent unemployment. Second, since the approach does not explain income distribution and relative prices in terms of equilibrium between "supply and demand", it need not assume any predetermined effect of income distribution (and hence relative prices) on the quantities produced. The implication of the first feature is clear: the approach is definitely more capable than neoclassical theory to deal with actual economic systems, in which the presence of unemployment seems to be the rule rather than the exception. The consequences of the second feature for the problem at hand may be less evident, but not less important: since no general relations between quantities produced and income distribution are envisaged, one is authorized to isolate the effects of distributive changes (caused by movements in the exchange rate) on the pattern of specialization (a 'static' analysis, so to speak) from those, more 'dynamic', effects of these changes on the quantities produced. The latter must be assessed case by case, since they are not subject to any general rule. In fact, they will depend, among other things, on the kinds of returns ruling in each particular sector, or on the effects of technological progress. Here we will examine the first kind of effects, both because they are more general and more related to the nature of the problem at stake. 
To enrich the analysis and check the robustness of the theoretical results, we distinguish among economies that only produce manufactures from those in which the most profitable sector exploits natural resources under conditions of differential rent. We show that, when both tradable sectors produce industrial goods, conventional devaluations do not generally allow the development of one sector without damaging the other. While when the prevailing sector operates under conditions of differential rent, even though the development of a new sector by adjusting the exchange rate towards its "industrial-equilibrium" level is possible, this requires that the policymaker very precisely determines the effect of changes in the exchange rate, both in direction and magnitude, on the other distributive variables.

The paper is structured as follows: in the second section we present the analytical framework and examine the role of the exchange rate when both tradable commodities are industrial goods, while in the third section we consider the case of a tradable primary good produced under conditions of differential rent. Section fourth discusses alternative policies that allow the diversification of the productive structure. Finally, the last section resumes the argument and presents the main conclusions of the article.

\section{ANALYTICAL FRAMEWORK}

Consider a price taking ${ }^{1}$ peripheral economy, open to trade (and, eventually, capital flows), with persistent unemployment. We assume conditions of free competition, namely, the free mobility of capital across sectors within the economy (and eventually, across countries). The productive structure is characterized by the following features: there are two potentially tradable consumption goods $T=C, I$, which are produced by direct labour, an imported capital good $(K)$, and a nontradable capital good (NT), the latter produced by labour and itself. As we shall see, which of the two $T$ - commodities is produced will be the outcome of a problem of technical choices.

Wages are paid post-factum. If $w$ stands for the uniform nominal wage rate across sectors, $r$ for the normal profit rate, $l_{N T}$ and $l_{T}$ (with $T=C, I$ ) the unitary labour requirements of sectors $N T$ and $T, k_{T}$ the unitary requirement of the capital good $K$ in sector $T, p_{K}^{*}$ its exogenously given price, $b_{T}$ and $d_{N T}$ the quantities of

\footnotetext{
${ }^{1}$ With the assumption that the economy is "price taker" we only mean that the domestic methods of production for tradable goods and domestic income distribution do not affect the international price of tradable commodities. We do not mean, therefore, that the economy faces an infinitely elastic demand curve for these goods, as it is usually interpreted by some scholars (see, e.g., Frenkel and Ros, 2006), because this assumption is tantamount to assuming that every excess of production over domestic internal demand is automatically absorbed by exports (in other words, Say's Law).
} 
good NT used in the production of $T^{2}$ and NT and $E$ the nominal exchange rate ${ }^{3}$; then the costs of production or the supply prices of commodities $N T\left(p_{N T}^{S}\right)$ and $T$ $\left(p_{T}^{S}\right)$ can be represented by the following equations:

$$
\begin{aligned}
& p_{N T}^{S}=w l_{N T}+p_{N T}^{S} d_{N T}(1+r) \\
& p_{T}^{S}=w l_{T}+\left(k_{T} E p_{K}^{*}+b_{T} p_{N T}^{S}\right)(1+r) \quad(T=C, I)
\end{aligned}
$$

If realized by the market, these prices ensure that commodities can be regularly delivered, since investment in each sector can afford the normal profit rate of the economy. They are non-other than the 'prices of production' of the classical economists and Marx -or the 'normal prices' of the neoclassical approach - rigorously formalized by Sraffa (1960).

For reasons that will be clear below, it is useful to introduce a second notion of price, which we shall denominate demand or selling price $\left(p_{T}^{d}\right)$. It represents the maximum amount of money that consumers are willing to pay for a certain commodity. If we abstract from transport costs, import tariffs and other expenses implied by international trade, these prices are:

$$
p_{T}^{d}=E p_{T}^{*} \quad(T=C, I)
$$

Where $p_{T}^{*}$ is the given international price of commodity $T$. Notice that, since $p_{T}^{*}$ is given for the domestic economy, once the level of the exchange rate is fixed, demand prices for tradable goods $(T=C, I)$ are univocally determined.

For the non-tradable commodity, the demand price is determined by its respective supply price, as it is the case with any commodity produced in a closed economy. Therefore, there is no point in distinguishing between the two, and we will simple refer to the price of $N T$ as $p_{N T}$ (that is, $\left.p_{N T} \equiv p_{N T}^{d}=p_{N T}^{S}\right)$.

The five equations (1)- $\left(2_{C, I}\right)-\left(3_{C, I}\right)$ have eight unknowns: $E, r, w, p_{N T}, p_{T, I}^{s}, p_{T, C}^{s}, p_{T, I}^{d}, p_{T, C}^{d}$. Therefore, there are three degrees of freedom left. To eliminate the first one, we assume that money wages are determined by the bargaining position of capitalists and workers; struggle that depends, among other things, on the strength of labour unions and the kind of institutions in the labour market (see for instance, Pivetti 2013). Formally,

\footnotetext{
2 The assumption that both tradable sectors employ the same kind of capital goods is no doubt restrictive. However, this is immaterial to the results reached in the paper and can be anyway easily relaxed when necessary.

${ }^{3} E$ is defined as the amount of domestic currency per unit of foreign currency, which means that $E$ goes up with a depreciation of the local currency.

${ }^{4}$ If wages were paid in advance, capital would coincide with costs, and therefore, the profit rate would be indistinguishable from the profit margin. This alternative treatment of wages, however, would not in the least alter the analytical results of the article. We thank a comment made by an anonymous referee, which gave us the opportunity to clarify this point.
} 


$$
w=\bar{w}
$$

\section{The closure of the system by means of the pattern of specialization}

To eliminate the last two degrees of freedom we must determine the pattern of specialization. As it will be clear below, it is convenient to define first the variable $e \equiv E / w$, which is none other than the inverse of the money wage in foreign currency, and moreover, since $w$ is given, $e$ will be immediately determined the moment $E$ is known. We will distinguish between two cases: (a) the case in which both tradable goods are industrial goods and (b) the case in which one of the two commodities (say good C), is a primary commodity produced by a fixed factor (typically land) under conditions of differential rent (for simplicity we ignore absolute rent). We will here consider case (a), while the discussion of case (b) will be postponed to section III.

\section{Two industrial goods}

The fact is that it is not possible to ascertain which of the two tradable industrial commodities will be effectively produced before the relationship between demand and supply prices of each of these commodities is established. Hence, before income distribution is known. The pattern of specialization of the economy will be regulated by the following conditions:

$$
p_{T}^{d} \leq p_{T}^{S}(T=C, I)
$$

The generic tradable commodity $T$ will be produced and (potentially) exported only if $p_{T}^{d}=p_{T}^{S}$. In contrast, when $p_{T}^{d}<p_{T}^{S}$, the sector will not be viable because its normal cost of production exceeds its demand price ${ }^{5}$. In other words, it cannot afford paying the normal profit rate of the economy. The case when $p_{T}^{d}>p_{T}^{s}$ can only be transitory, since, due to competition, this discrepancy will eventually be eliminated by a rise in the supply price of commodity $T$. Notice that this adjustment differs from the mechanism assumed to operate in a closed economy, where it is the demand price that falls to restore the equality with the (lower) supply price. But this cannot happen in the model under consideration because this adjustment would violate the price-taking assumption (if the demand price falls down to the lower domestic costs, this would mean that domestic conditions would eventually regulate the international price of $T$, i.e., the economy becomes a price-maker) ${ }^{6}$.

\footnotetext{
${ }^{5}$ Of course, there are other non-price factors that may allow a country to export specific commodities (e.g., product differentiation, etc.). The implications of this point are beyond the scope of this paper, since this issue is not considered by the models under examination.

${ }^{6}$ Although it is beyond the scope of this article, the fact that, for an industrial good, the adjustment goes from supply to demand prices and not the other way around, suggests that the assumption of "price-taking" behavior as it is usually employed by the literature may not be sufficiently robust, and
} 
We can now derive for each industrial good $T$, an $e-r$ relationship that gives, for an arbitrary level of $e$, the maximum affordable profit rate by each tradable sector under given technical conditions and international prices (or the minimum $e$ that allows each sector to earn a given profit rate). This is obtained by equalizing supply and demand prices for each commodity $T$. Hence, from conditions (1) and (3) on the one hand, and (2) and (4) on the other, it is possible to obtain the following function:

$$
e=\frac{l_{T}}{1-(1+r) k_{T}}+\frac{b_{T} l_{N T}(1+r)}{\left[1-(1+r) d_{N T}\right]\left[1-(1+r) k_{T}\right]} \quad(T=C, I)
$$

where, for convenience, we have chosen the units such that the given international prices are equal to unity.

The shape of these curves depends on technical coefficients (and international prices). It can be seen from (6) that $e(0)>0^{7}, e^{\prime}(r)>0$ and $e^{\prime \prime}(r)>0$ in the positive quadrant, and finally, $r$ reaches a maximum when $e$ goes to infinity (on this point, see equation [9] below). Figure 1 represents a possible shape of these curves.

Figure 1: e -r Relation in the open "price-taking" economy

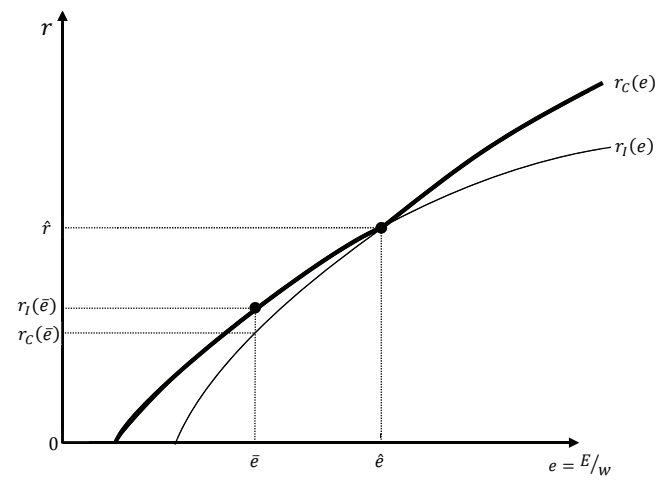

therefore should be carefully reexamined. The assumption, however, that the economy is already a price-maker of commodity $T$ does not seem very promising either. First because in this case there would be no need of devaluation for boosting sectorial competitiveness. Second, since in this case domestic conditions of production and distribution would affect international prices, to assess the final impact of devaluation the policymaker would have to face the herculean task of identifying the input-output relations for the world economy. It could be finally envisaged the situation in which the economy initially does not produce good $T$ (i.e., the country is, by definition, a price-taker of commodity $I$ ) and uses devaluation to become a price-maker. While the possibility also needs considering the input-output relations for the world economy, it additionally seems to be implausible, among other things, because this strategy could be easily counterbalanced by devaluation policies of trade partners.

$7 e(0)=\frac{l_{T}}{1-k_{T}}+\frac{b_{T} l_{N T}}{\left(1-d_{N T}\right)\left(1-k_{T}\right)}$ which is positive provided that the economy is viable: this means that $k_{T}<1$, which means that one dollar of production of the tradable good (recall that its international price is set equal to one) requires less than one dollar of imports; And $d_{N T}<1$, which means that to produce one unit of the tradable good requires less than one unit of itself. 
For each commodity $T$, the feasible regions of production are the ones below the curves, since the condition $p^{s}<p^{d}$ holds, while above the curves the supply price is higher than the respective demand price, and therefore, commodity $T$ cannot be profitably produced.

These curves can be used to determine the pattern of specialization of the peripheral economy as a problem of technical choices. In effect, due to the action of competition among capitals, the tradable sector of the economy will specialize in the production of that commodity which, for the given value of $e$, can afford the highest profit rate (or alternatively, that is able to pay the highest wage in foreign currency - the lowest $e$ - for a given profit rate). Then, the figure shows that for any level $e<\hat{e}$ there will be full specialization in the production of commodity $I$. In effect, if for instance, $e=\bar{e}(<e)$, then $r_{I}(\bar{e})>r_{C}(\bar{e})$ and there will be no incentive to invest in sector $C$. The opposite occurs when $e>\hat{e}$. An only by a fluke $e=\hat{e}$, which is the level that allows the coexistence of the two tradable sectors in the economy.

In the example depicted by Figure 1, sector $I$ is more profitable than sector $C$ for lower values of $e$ because the share of imported means of production in output is higher in sector $I$. As the exchange rate rises, therefore, the costs of imported capital goods increase, thereby raising the relative profitability of sector $C$ (but we must recall that relative costs also vary with the change in the profit rate, since it affects the cost of domestic capital goods - NT - , and this may cause that the curves intersect more than once; this point will be discussed below).

The outer envelope of the curve (thick black line) illustrates the economically relevant pairs of $e$ and $r$. In analytical terms, the $e-r$ relationship is given by:

$$
r=\left\{\begin{array}{l}
r_{I}(e) \text { if } e \leq \hat{e} \\
r_{C}(e) \text { if } e>\hat{e}
\end{array}\right.
$$

If we recall that the approach followed here assumes the exogeneity (nonmarket determination) of either the profit rate or the real wage, to determine the remaining two degrees of freedom we proceed in the following way: (a) either the real wage is fixed from outside the price system by setting the level of $e^{9}$ and, therefore, the corresponding level of $r$ is endogenously determined by condition $(7)^{10}$; or,

8 From condition (6), one obtains:

$r_{T}(e)=\frac{e k_{T}+b_{T} l_{N T}+d_{N T}\left(e-2 e k_{T}-l_{T}\right)-\sqrt{d_{N T}^{2}\left(e-l_{T}\right)^{2}-2 d_{N T}\left(e k_{T}-b_{T} l_{N T}\right)\left(e-l_{T}\right)+\left(e k_{T}+b_{T} l_{N T}\right)^{2}}}{2 d_{N T} k_{T} e}$

9 As we shall discuss immediately below, since both consumption goods are tradable goods, the real wage is univocally determined the moment $e$ is fixed.

$10 e$ can be determined in the following way: considering a given level of money wages by (4), the Central Bank can regulate the level of wages expressed in foreign currency by setting the pace of the nominal exchange rate. Of course, monetary policy is not conducted "in a vacuum". What this means is that the ability of the Central Bank to regulate income distribution is always conditioned by both structural and 
alternatively, (b) $r$ is fixed from outside the system ${ }^{11}$ and condition (7) determines the corresponding level of $e$ (and therefore, the real wage). The level of the exogenous distributive variable (either $e$ or $r$ ) in turn determines the pattern of specialization of the economy.

So far, the dynamics of the real wage has not been dealt with explicitly. The assumption of persistent unemployment only implies that the real wage does not necessarily adjust to clear the labor market, as it is the case in the marginal approach, but that is rather mostly determined by the interplay of political, historical and socioeconomic factors. In this respect, if $\lambda=\left(c_{C}, c_{I}\right)$ stands for one unit of the (given) consumption basket of the representative worker, the level of the real wage (i.e., the number of consumption baskets that can be afforded by each worker) can be defined as:

$$
\omega \equiv \frac{w}{E \lambda \cdot p^{*}}=\frac{1}{e \lambda \cdot p^{*}}\left(\text { with } p^{*}=\left[p_{C}^{*}, p_{I}^{*}\right]\right)
$$

Notice then that, since $p^{*}$ and $\lambda$ are both given, once the level of $e$ is known, the level of $\omega$ is univocally determined by (8). Moreover, a rise in $e$ decreases the real wage in the same proportion ${ }^{12}$. All this suggests that the $e-r$ curve can be also interpreted as a traditional wage-curve (or "factor-price frontier") for the open peripheral economy.

\section{The exchange rate as a "light switch" and its limits}

The model developed so far allows us to discuss the potential role of the exchange rate as a tool for boosting specific sectors of the economy. To see this, assume that the exchange rate is at the level $e_{0}(<\hat{e})$ in Figure 1 , and the corresponding level of the profit rate is given by $r=r_{1}\left(e_{0}\right)$. The tradable sector, therefore, fully specializes in the production of commodity $I$. For sector $C$ to be developed, it is necessary to depreciate the domestic currency at least up to a level of the exchange rate equal to $\hat{e}$. Simple and appealing as the idea may be, it faces several important limitations.

To have a first glance at this feature, notice that, unless the policymaker exactly manages to raise $e$ up to $\hat{e}$, the only way to allow the competitiveness of sector $C$ is at the expense of the exclusion of the already existing sector $I$.

\footnotetext{
institutional constraints. Among the former, perhaps the most important one for peripheral economies is the impossibility to finance persistent current account deficits. Among the latter, one should mention investors' expectations regarding the future evolution of the exchange rate and their potential effects on the direction of capital flows (on both points, see for example, Canitrot, 1983) or the possibility of strong wage resistance (see Diamand, 1978). While a thorough examination of the issue is beyond the scope of the paper, for exchange rate policy to be used to diversify the productive structure, these constraints must be not binding.

11 In this case, one can assume that the profit rate follows the pace of the exogenously given interest rate fixed by the Central Bank, or alternatively, it follows, under conditions of free capital mobility, the pace of the international profit rate.

12 This condition would no longer hold had the consumption basket included non-tradable goods. But it would still be the case that $e$ and $\omega$ would move in opposite directions.
} 
Things are even more serious when more than two tradable commodities can be produced, because in this case there will generally not be a value of $e$ that allows the coexistence of all tradable sectors ${ }^{13}$. To see this, we have recourse to Figure 2.

The figure shows that, if two sectors initially happen to coexist, as it would be the case with sectors $C$ and $I$ if the initial exchange rate is $e_{0}$, the development of the new sector $M$, which requires an exchange rate equal or higher than $e_{1}$, necessarily entails that sector $C$ would no longer be competitive. And sector $I$ will disappear too if, after devaluation, $e$ is strictly higher than $e_{1}$.

Figure 2: The exchange rate as a "light-switch"

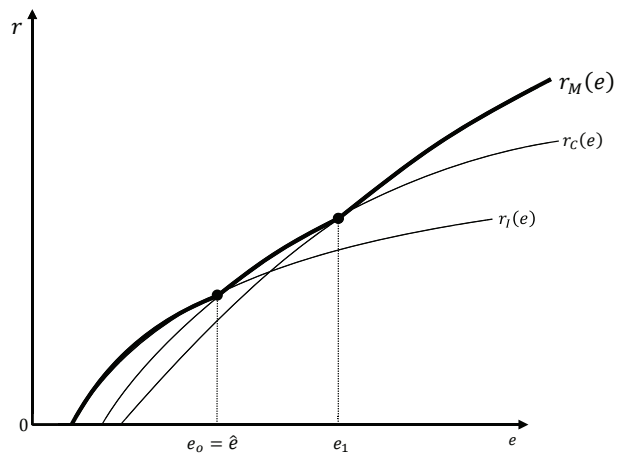

In other words, the implicit idea behind this policy, namely that the depreciation of the exchange rate is not damaging for other sectors, does not stand close scrutiny when tradable goods are industrial goods (things will be different when one of the two goods is a primary good produced under conditions of differential rent).

A further difficulty is the following: if conditions of free international capital mobility are considered, it is expected that the normal level of the domestic profit rate is at least partially determined by the pace of the international level $\left(r^{*}\right)$, with the implication that $e$ becomes the endogenously determined distributive variable in (7). In this case, devaluation policy is also bound to fail. This is shown with the help of Figure 3. The attempt to depreciate the currency from $e_{0}$ to $e_{1}$ to develop sector $C$ also raises $r$ above the initial level $r_{0}=r^{*}$, and therefore, induces a capital inflow that ends up appreciating the domestic currency, until the equality between $r$ and $r^{*}$ is finally re-established. While this outcome could be overcome by monetary policy if it is committed to systematically intervene in the foreign exchange market to sustain the higher value of the currency, one could envisage that the continuous inflow of foreign direct investment in the tradable sector would, however, eventually lead the economy to become the world supplier of commodity $C$, therefore contradicting the price-taking assumption.

13 An exception to this result holds when one admits the possibility of heterogeneous remunerations within each social class (i.e., different rates of wages in foreign currency or profit rates across sectors). As we show in the fourth sction, this could be achieved by differentiating exchange rates. 
Figure 3: Devaluation under free international capital mobility

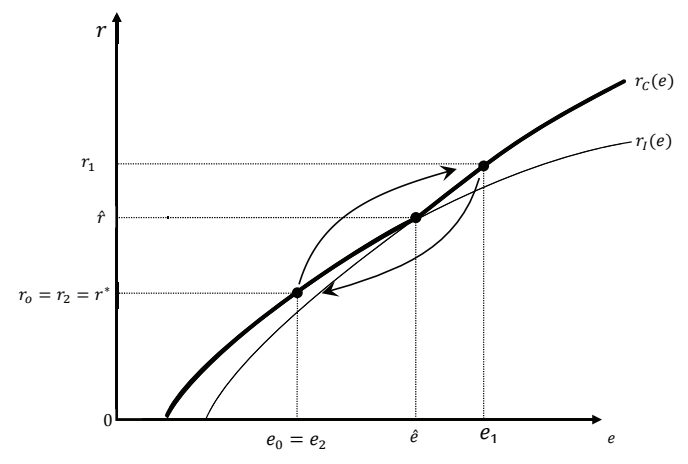

In any case, there is a third difficulty. Since a rise in $e$ causes a decrease of the real wage by the same magnitude, it may well happen that the required rate of devaluation is not socially tolerable. If, in Figure 4, the variable $\alpha$ measures the minimum number of consumption baskets that allows workers to enjoy a normal standard of living, then $1 / e_{\alpha}$ measures the minimum wage in foreign currency that allows purchasing $\alpha$ baskets. Therefore, if $\hat{e}>e_{\alpha}$, devaluation policy will face an insurmountable limit, and hence, sector $C$ will not flourish.

Figure 4: Wage-resistance

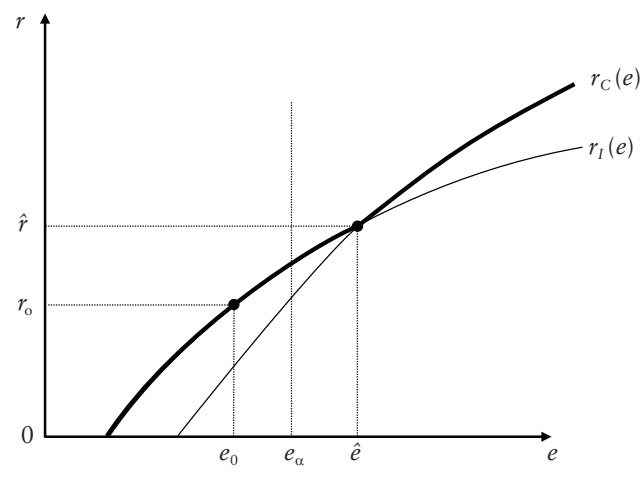

So far, we have been assuming that there is only one switch-point among productive sectors. However, at least two other alternative situations are conceivable. First, that one curve is above the other for all possible levels of $e$. In other words, a situation in which there is no switch-point (see Figure 5). It is clear in this case that devaluation is in a blind alley, since it only causes a decrease of the real wage, without inducing structural change. 


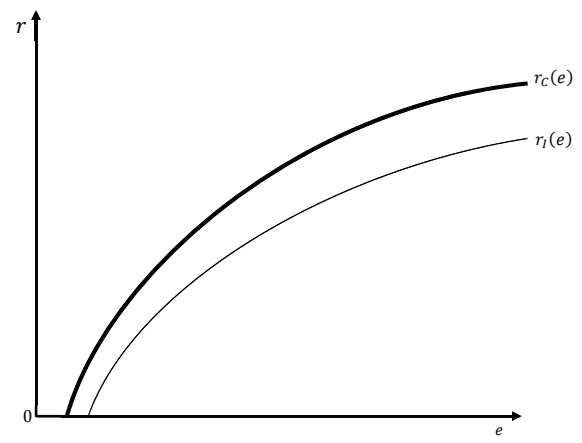

The other, perhaps more interesting, case occurs when there are two or more switch-points as in Figure 6. No definite conclusions regarding the direction of the exchange rate required to boost a particular sector can be reached here. For instance, devaluation enhances sector $C$ if the exchange rate is below $\hat{e}_{0}$, while appreciation of the currency is necessary if $e$ happens to be initially higher than $\hat{e}_{1}$. On the same footing, when $\hat{e}_{0}<e<\hat{e}_{1}$, the attempt to develop sector $I$ could be equally achieved both through depreciation and appreciation policies ${ }^{14}$.

Figure 6: Multiple switches in the tradable sector

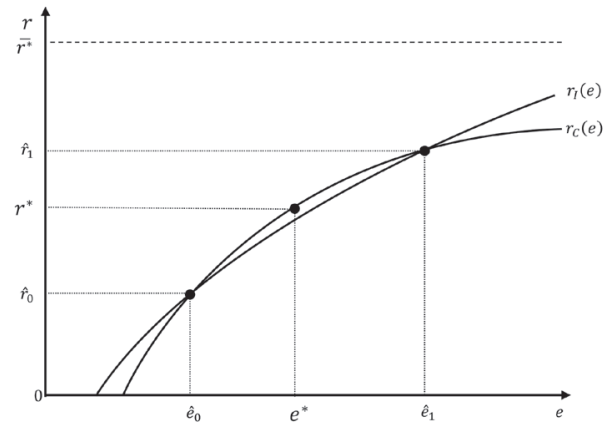

Moreover, consider this second case under free capital mobility across countries for the initial distributive configuration $\left(e^{*}, r^{*}\right)$. Assume further that the policymaker has no other choice than to appreciate the currency to avoid social turmoil. Then, the required appreciation to promote sector $I$ could not persistently reduce the domestic profit rate below $r^{*}$ since, differently from the case discussed

\footnotetext{
14 Notice moreover that, by itself, this case seems to contradict the claim often adduced by some of the proponents of exchange rate policy as a tool for diversification of the productive structure, that sectors can be ordered in terms of their "technological intensity", independently of income distribution (see, for instance, Cimoli et al., 2013).
} 
in Figure 3, the capacity of the Central Bank to sustain the exchange rate under capital outflows necessarily vanishes when the monetary authority runs out of international reserves.

Figure 6 can be also used to study a final problem. To do this, we must recall first that there is maximum profit rate that each sector can afford. This is the rate that, given international prices (which, recall, have been normalized to unity) would be obtained if labour costs were arbitrarily reduced to zero (either because the money wage in terms of any commodity tended to zero, or because the nominal exchange rate were arbitrarily high). For any sector $T$, this rate, $R^{T}$ is given by ${ }^{15}$ :

$$
R^{T}=\frac{1-k_{T}}{k_{T}}
$$

Consider now the case in which, due to capital mobility, the given international rate in Figure 6, $\overline{r^{*}}$, sets a lower bound for the domestic profit rate; then, if $\bar{r}^{*}>R^{T}$, domestic producers would not be willing to produce commodity $T$ for any (feasible) level of $e$, and the country would be excluded from international trade.

\section{PRODUCTION OF A PRIMARY GOOD UNDER CONDITIONS OF DIFFERENTIAL RENT}

Consider now the case in which good $C$ is a primary good. The difference with the two-industrial-goods case is the following: since, besides labour and capital goods, $C$ is produced by a fixed factor, typically land, if there is a positive gap between demand and supply prices of $C$, namely $p_{C}^{d}>p_{C}^{S}$, this magnitude is not necessarily eliminated by competition through a rise in the profit rate (or in $e$ ) as in the model of section II, but is eventually appropriated by land-owners in the form of differential rent. In formal terms:

$$
\rho=p_{C}^{d}-p_{C}^{S}
$$

This, in turn, encounters the following difficulty. When both commodities are industrial goods, for a given $e$, the profit rate is univocally determined by condition (7) and both variables are necessarily positively related. When $C$ happens to be the traded commodity, and the equality between supply and demand prices no longer holds, condition (7) is not necessarily valid, with the implication that the system gains an additional degree of freedom (there is an additional distributive variable, $p$, to be determined). Formally, the five-price-equation system $(1)-\left(2_{\mathrm{C}}\right)-\left(3_{\mathrm{C}}\right)-(4)-(10)$

\footnotetext{
15 This condition is derived from the condition $p_{T}^{d}=p_{T}^{s}$, when $1 / e$ goes to zero.

16 This condition holds as long as $k_{T} \leq d_{N T}$. If $d_{N T}>k_{T}$, the maximum rate depends on the conditions of production of commodity NT and is given by: $\frac{1-d_{N T}}{d_{N T}}$. But there is still a maximum profit rate.
} 
have the following seven unknowns: $e, w, r, \rho, p_{C}^{s}, p_{C}^{d}, p_{N T}$ (notice that the choice of these equations as the relevant ones imply that sector $C$ is assumed to be the more profitable sector).

Figure 7 shows the interaction among distributive variables in the presence of differential rent in sector $C$, and hence, when there is an additional degree of freedom left (the fact that the feasible distributive configurations are now illustrated by the grey area in the figure rather than by a curve, shows this additional degree of freedom). The following features can be seen from the figure. For a given $e=\bar{e}$ : (i) $\bar{e}>e$, since $C$ is assumed to be the most profitable tradable sector; (ii) there is a range of possible values for the effective profit rate, $\bar{r}$, that are compatible with the assumed productive structure. This rate is necessarily below $r_{C}(e)$ and above $_{I}(e)$. This means that, while sector $C$ is persistently "supra-competitive", and hence yields extra-profits in the form of differential rent, commodity $I$ will not be profitability produced ${ }^{17}$.

Figure 7: Wages, sectorial profit rates and land rent

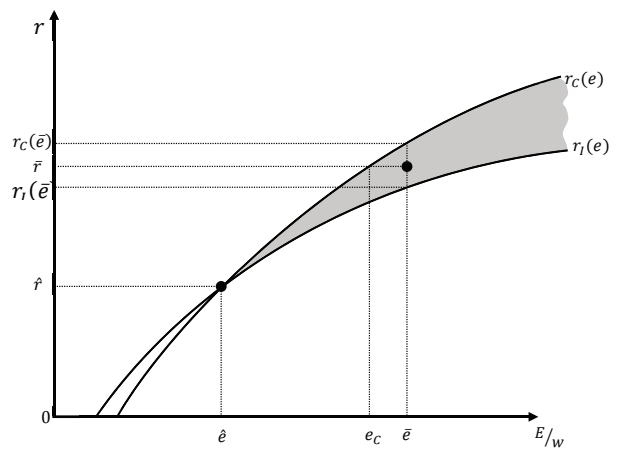

In Figure 8, the rent can be "observed", so to speak, in two different ways: (i) given $\bar{e}$, through the difference between the effective profit rate, $\bar{r}$, and the maximum profit rate, $r_{C}(\bar{e})$, that industry $C$ could afford; (ii) for a given $\bar{r}$, as the difference between $e$, and the highest level $\left(e_{\mathrm{C}}\right)$ that the sector could support.

The closure of the system still needs to ascertain how the level of $r$ varies with $e$ when there is differential rent. And this relation does not seem to obey any general rule. One can in fact think of reasons why the profit rate rises, remains constant or even decreases with $e$.

To see this more closely, let us express the domestic profit rate as the sum of two independent factors: the level of the riskless interest rate, $i$, and a profit of

${ }^{17}$ Actually, $\bar{r}$ can also be over $r_{I}(e)$. In this case, sector $I$ earns the normal profit rate, and therefore, can coexist with the rentistic sector $C$ (see below). But if this rate were below $r_{I}(e)$ the distributive configuration would not persist, since it would imply that sector $I$ would be earning a higher profit rate than sector $C$, and therefore, its supply price would necessarily rise. 
enterprise, $\sigma$, that compensates for the "risks and troubles" of investing in the productive sphere of the economy (for simplicity, we assume that $\sigma$ is homogenous across sectors). Formally, we have:

$$
r=i+\sigma
$$

If we assume that the elements that determine these risks and troubles are sufficiently stable over time, then the level of $r$ will depend on the behavior of. We can now use equation (11) to characterize the three possible abovementioned interactions between $r$ and $e$.

First, if $i$ is exogenously determined by the monetary authority, both elements on the right-hand side of equation (11) will be given before prices and distribution are determined (see for instance, Pivetti (1985) and Panico (1988) and therefore, a rise in $e$ would have no effect on the normal profit rate. Formally, we will have:

$$
r=\bar{\imath}+\bar{\sigma} \quad(11 \mathrm{~A})^{18}
$$

In this case, when $e$ rises, the whole burden of the adjustment will fall on the real wage $\omega$ - see equation (8)-, which will decrease at the expense of $\rho^{19}$.

A second possibility is to envisage a situation in which the profit rate rises with $e$. For instance, under free mobility of financial flows, the domestic interest rate cannot be persistently lower than the international interest rate $\left(i^{*}\right)$ plus the expected rate of devaluation $\left(\Delta e^{E}\right)-$ i.e. $i \geq i^{*}+\Delta e^{E}$. Therefore, if the rise in $e$ induces higher devaluation expectations and the former inequality is violated, to prevent capital outflows the Central Bank will be forced to raise $i$ (and thereby $r$ will rise too) (cf., Canitrot, 1983) ${ }^{20}$. This behavior can be formalized in the following way:

$$
r=i(e)+\bar{\sigma},\left(\text { with } i^{\prime}(e)>0\right)
$$

In this case, devaluation raises both land rent and the profit rate at the expense of the real wage, $\omega$.

Lastly, the opposite situation is also plausible. This happens when devaluation

\footnotetext{
18 A similar result will hold if, due to capital mobility, the domestic profit rate is determined by the international rate, $r^{*}$.

19 This first case seems to be the one implicitly considered in Bresser's contributions to the topic (see, for instance, Bresser, 2008), in which the "industrial equilibrium" exchange rate can be conceived as independent of the profit rate.

20 Clearly, the possibility that the rise in $\Delta e^{E}$ is compensated by a rise in the effective exchange rate cannot be excluded (Canitrot (1983) himself considers this alternative). In this case, the level of $e$ would be endogenous to the magnitude of the risks perceived by investors, which were reflected in the future magnitude of the exchange rate. Nor can one neglect a priori the possibility that the rise in $\Delta e^{E}$ further induces a rise in $e$, therefore triggering a process of cumulative causation that finds no definite limit (on this point, see Serrano and Summa, 2015). However, this does not change the analysis, which only attempts to show that the interaction between $i$ and $e$ described by condition (11B) is plausible. We thank a comment by an anonymous referee that allowed us to clarify this point.
} 
is sufficiently strong to induce the expectation of future currency appreciation or nominal exchange rate stability (because, for instance, investors perceive that the exchange rate is now above the level determined by the so-called fundamental ${ }^{21}$ ). Under these conditions, the Central Bank has room to reduce the domestic interest rate without facing the risk of capital flights. This means that,

$$
r=i(e)+\bar{\sigma},\left(\text { with } i^{\prime}(e)<0\right)
$$

and, therefore, devaluation raises $\rho$ and decreases both $r$ and $\omega^{22}$.

Which of the three possible interactions between $e$ and $r$ actually prevails in the real world cannot be determined a priori, but must be rather ascertained case by case. As we shall see, this result has important consequences for the usage of $e$ as a tool to boost a particular industrial sector. To this we turn next.

\section{The exchange rate under conditions of differential rent}

Let us examine what happens when the exchange rate is used to develop a sector of the economy when there is differential rent. A first thing to be noticed is that, differently from the two-industrial-goods case, now it is indeed possible to develop a certain sector of the economy without in principle affecting the normal profitability of the existing ones.

If, for a given $e=\bar{e}$, sector $C$ yields the profit rate $\bar{r}$, it is possible to determine the minimum level of $e$ that would allow the other tradable sector (in this case, industry $I$ ) to yield this same level of the profit rate. This level, $e_{I}$, is none other than the level that equalizes supply and demand prices for this sector, and is determined by condition (6) of section II, when applied to the specific sector $I$ :

$$
e_{I}=\frac{l_{I}}{1-(1+\bar{r}) k_{I}}+\frac{(1+\bar{r}) d_{N T}}{\left[1-(1+\bar{r}) k_{I}\right]\left[1-(1+\bar{r}) b_{I}\right]}
$$

Note that, at the level $e_{I}$, both sectors would earn the same profit rate, $\bar{r}$, and therefore could coexist (besides the normal profit rate, sector $C$ would also earn a differential rent). But then, this would further seem to suggest that, for sector $I$ to be equally profitable than sector $C$, devaluation of magnitude $\Delta e_{I}$ is needed, with:

$$
\Delta e_{I}=e_{I}-\bar{e}
$$

\footnotetext{
${ }^{21}$ Whether or not these fundamentals actually influence the behavior of the exchange rate, and therefore, of the interest rate, is irrelevant for the argument; the important thing is that investors think they do. On the "conventional" determination of the interest rate, cf., Aspromourgos (2007).

22 That in all the three cases devaluation decreases the real wage is expected, since the fact that both consumption goods are tradable goods imply that $\omega$ is univocally determined by $e$, and both variables move in opposite directions.
} 
Equation (12) measures the difference between the actual level of the exchange rate, and what Bresser (2008) calls the "industrial-equilibrium" exchange rate. And it seems to provide a sectorial index of competitiveness: the lower the value of $\Delta e_{T}$ for a specific tradable sector $T$, the greater its "comparative advantages" relative to other sectors seem to be. In graphical terms,

Figure 8: «required» devaluation of sector I

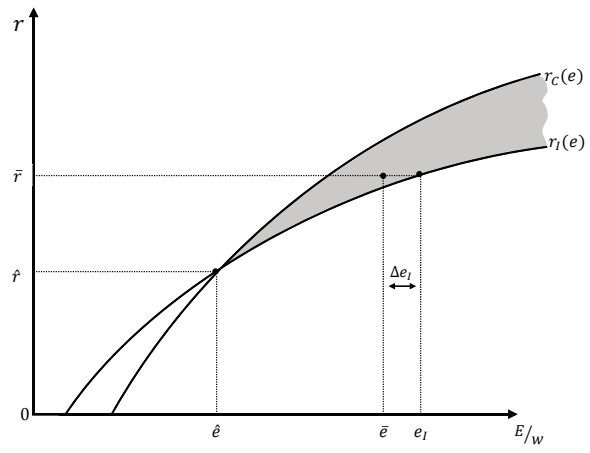

The problem for the policymaker emerges in this case when she attempts to calculate, for practical purposes, the required magnitude of devaluation for a generic tradable industrial sector $T$, since this now needs very carefully considering both the direction and magnitude of the possible interactions among distributive variables. In fact, the attentive reader may have already noticed that the magnitude of $\Delta e_{I}$ in (12) is a function of the normal profit rate, whose behaviour, as we have seen in the previous subsection, must be ascertained case by case. Therefore, at least the following three scenarios are conceivable:

Scenario 1: consider first the case in which the profit rate is an increasing function of $e, g(e)$, as in equation (11B). The initial distributive configuration is represented by point A in Figure 9. In this case, equation (12) underestimates the magnitude of devaluation to include sector $I$ in the productive structure, since it does not incorporate the endogenous movement of $r$ when $e$ varies. In the figure, the $e$-coordinate of point $B, e_{I}$, represents the required exchange rate according to (12), while the corresponding $e$-coordinate of point $C, e^{*}$, indicates the (higher) level of the exchange rate effectively needed, once the change in normal profitability according to $g(e)$ - whose possible trajectory is depicted by the dotted black arrow - is considered.

As a result, Figure 9 shows two possible outcomes. If the effective exchange rate is initially raised up to $e_{I}$, either devaluation stops there and the final distributive configuration is reflected by $D$ (which, differently from $B$, does capture the actual interaction between $r$ and $e$ ). This only causes a decrease in the money wage in foreign currency - and in the real wage -, and a rise in $r$ (and eventually in $\rho$ ), but it is unable to modify the prevailing productive structure. Alternatively, the policymaker, who is decided to transform the productive structure, attempts to further devalue the cur- 
Figure 9: Depreciation and pattern of specialization under scenario 1

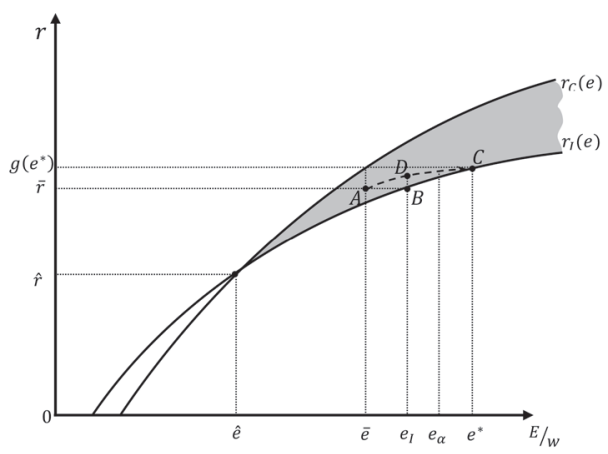

rency to complete the effective path of $g(e)$, described by trajectory DC. However, in this latter case, since the effective magnitude of the required devaluation may be considerably higher than the one originally projected, the possibility that the decrease in the real wage is so drastic that workers are prevented from consuming the minimum quantity of necessary consumption goods, cannot be excluded, and therefore, devaluation policy is bound to fail. As in Figure 3, this upper bound of the exchange rate is $e_{\alpha}$, which is lower than the required exchange rate $e^{*}$.

Scenario 2: policymakers could be tempted, when there is more than one possible industrial sector in the economy, to encourage the generic industry $M$ in Figure 10 , either because it is considered "strategic" for the economy; or simply because, on the basis of (12), it is the sector that exhibits comparative advantages; namely the sector that is believed to be closer to the competitiveness threshold, and therefore to require the lowest rise in $e$ to be profitably produced (this sector, incidentally, is also believed to be the least costly in distributive terms). To this end, $e$ is raised from its initial level, $\bar{e}$, up to $e_{M}$. However, if the actual distributive interactions are instead reflected by condition (11C), it is conceivable that the rise in $e$ ends up promoting, since it negatively affects both the real wage and normal profitability, the less-desired sector N. In Figure 10, this is shown by point C.

Figure 10: Depreciation and pattern of specialization under scenario 2

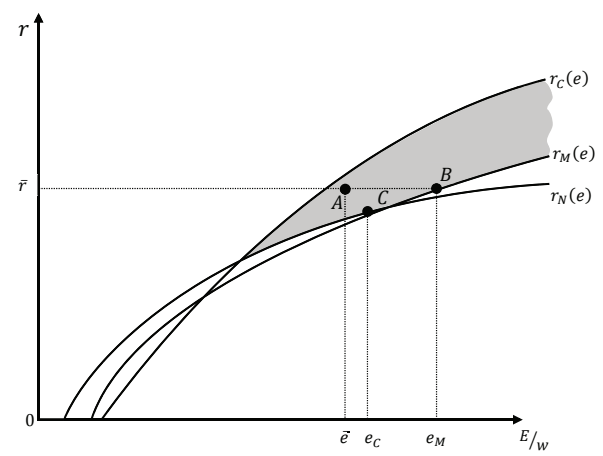


Scenario 3: Finally, the most problematic scenario seems to emerge in the following case. Suppose distributive conditions are such that, besides the rentistic sector $C$, there simultaneously is another industrial sector $N$ that is already competing abroad. However, due to its higher number of linkages with the remaining sectors of the economy, policymakers decide to develop a different industrial sector $M$. The economy is initially at point A in Figure 11 and therefore, the policymaker uses the competitiveness index (11) to determine the level of $e$ needed for sector $M$ to earn the ruling profit rate, $\bar{r}, e_{M}$. Therefore, she fails to capture the actual relationship between $e$ and $r$, reflected by function $g(e)$ in the figure. Here exchangerate policy faces two potential problems. First, this rate of devaluation fails to develop sector $M$, since at the higher level $e_{M}$, the actual profit rate rises to $g\left(e_{M}\right)$, which is unaffordable by the sector. Second, and perhaps more serious, this policy also excludes the existing sector $N$ from the productive structure, since $g\left(e_{M}\right)$ is higher than the maximum profit rate affordable by industry $N-r_{N^{-}}$. The conclusion is that devaluation not only does not improve, but also deteriorates national competitiveness.

Figure 11: Depreciation and pattern of specialization under scenario 3

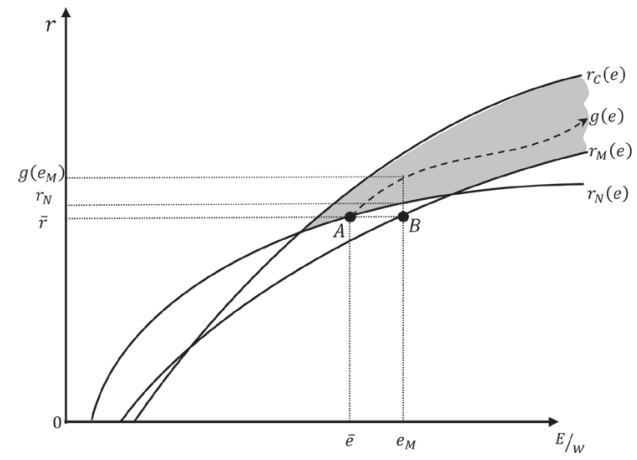

\section{EXCHANGE RATE DIFFERENTIATION AND \\ THE COEXISTENCE OF INDUSTRIAL SECTORS}

In the second section we have shown that coexistence of sectors may not be achieved by conventional devaluations. In this section, however, we discuss how this result can be achieved by differentiating effective exchange rates, as suggested, among others, by Kaldor (1970) and Diamand (1978).

Consider first the case of two industrial goods. The idea can be very simply shown by means of Figure 12.

Suppose the level of the profit rate is $r^{*}$. Then, as we have seen in the second section, without government intervention the level of $e$ that the economy would tend to realize is $e_{I}$, and only sector $I$ could compete abroad. But if the Central Bank decides to differentiate nominal exchange rates, for instance, by raising the level faced by sector $C$ for its exports up to $e_{c}$, both sectors could earn the same profit 
Figure 12: Exchange rate differentiation with two industrial goods

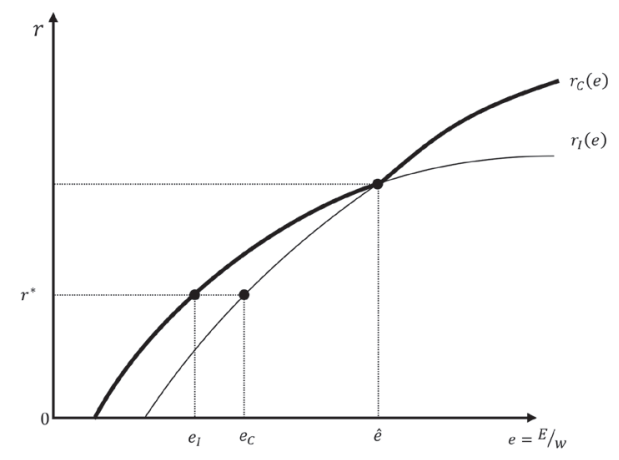

rate, and therefore coexist ${ }^{23}$. Notice that, the same result would be obtained if, for a given nominal exchange rate, each sector would pay a different level of money wages. In the example shown in Figure 12, sector $I$ could afford a higher level of money wages than sector $C$. Of course, this result could be generalized to develop three or possibly more tradable sectors in the economy ${ }^{24}$.

When one of the sectors works under conditions of differential rent, we have seen in the third section that sectorial coexistence is possible, without exchange rate differentiation. In this case, therefore, the reason for this policy is different. To see this, consider now Figure 13 and suppose that sector $C$ produces a primary good (a necessary good, e.g., "corn") that works under conditions of differential rent, and further assume that, at $r^{*}$, the actual level of $e$ is $e_{I}=E_{I} / w$.

Figure 13: Exchange rate differentiation under differential rent

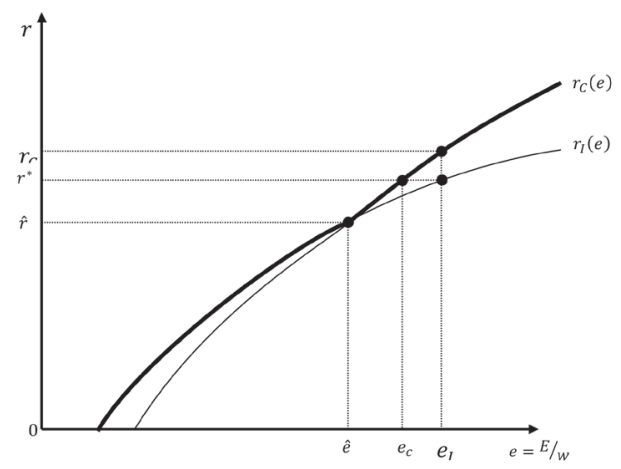

${ }^{23}$ Effective exchange rates could be equally differentiated by means of other policy tools such as taxes and subsidies.

${ }^{24}$ A similar outcome would be obtained if, instead of assuming a given profit rate, the exchange rate is exogenously given. For this level of $e$, the corresponding normal profit rate, say $\bar{r}$, will be determined by the sector that can afford the highest profit rate, while the level of the exchange rate required by the other sector will be precisely the one that allows the sector to earn $\bar{r}$. 
This means that a) sector $I$ can compete abroad and that b) sector $C$ earns an extraordinary rent, since the profit rate of the sector, $r^{*}$, is lower than the maximum rate it could afford, $r^{C}$. If $p_{C}^{S}\left(r^{*}\right)$ is the cost of production of commodity $C$ at $r^{*}$, the magnitude of the rent is:

$$
\rho=E_{I} p_{C}^{*}-p_{C}^{S}\left(r^{*}\right)
$$

Then, in this case, the Government could reduce the level of the exchange rate faced by sector $C$ from $e_{I}$ to $e_{c}\left(=\frac{E_{C}}{w}\right)$. Sector $C$ would still earn the same profit rate as before; however, since the demand price of $C$ would decrease, the real wage in terms of commodity $C$ - a necessary good - would increase. Therefore, in this case exchange-rate differentiation has the objective to redistribute resources from landowners to workers without affecting normal profitability. Of course, one could also consider the opposite initial situation: if at the level $r^{*}$ the exchange rate is $e_{c}$, then the Government could raise the exchange rate faced by sector $I$ up to $e_{I}$. This would have the double effect of incorporating sector $I$ into the economy without decreasing the real wage in terms of the necessary good $C$.

\section{CONCLUDING REMARKS}

By means of a two-tradable-goods model inspired by the Classical-Sraffian tradition, throughout this work we have discussed the role of the exchange rate as a tool to boost sectorial competitiveness. We have first shown that, when both tradable sectors are industrial sectors, it is generally not possible to include one sector into the productive structure without excluding the already existing one. Beyond this difficulty, which in itself seriously challenges the idea that the export basket can be diversified by simply depreciating the domestic currency, we have further seen that devaluation policy may clash with a distributive limit (imposed by the existence of a targeted real wage or a targeted profit rate), reach indeterminate results when the $e-r$ curves intersect more than once, and be totally ineffective if the curves happen not to intersect.

On the other hand, when the tradable good is produced by means of a fixed factor in short supply, typically natural resources, the structural-change channel may work properly, but it may be very difficult to implement. This is due to the fact that the existence of differential rent introduces an additional degree of freedom into the price system that renders the interaction among distributive variables indeterminate a priori. And, even if the kind of relation between $e$ and $r$ could be somehow predicted by the policymaker, this would not be enough to measure the required rate of devaluation, being also necessary to determine the exact magnitude of this relationship. If all this is not duly considered, it may well happen that the attempt to develop a particular sector of the economy not only will be ineffective, but it will also damage sectors that were already competitive. The overall conclusion is that due to these potential problems, exchange rate policy should be heavily supported by empirical 
analysis of the economy under consideration, that duly considers both the specificities of its productive structure and, not less important, its distributive interactions.

\section{REFERENCES}

Aspromourgos, T. (2007) "Interest as an artefact of self-validating Central Bank beliefs", Metroeconomica, 58(4): 514-535.

Bresser Pereira, L. C. (2008) “The Dutch Disease and its Neutralization: A Ricardian Approach", Brazilian Journal of Political Economy, 28(1): 7-71.

Canitrot, A. (1983) “El salario real y la restricción externa de la economía”, Desarrollo Económico, 23, No. 91: 423-427.

Cimoli, M.; Fleitas, S.; Porcile, G. (2013) "Technological intensity of the export structure and the real exchange rate", Economics of Innovation and New Technology, 22 (4): 353-372.

Diamand, M. (1978) "Towards a change in the economic paradigm through the experience of developing countries", Journal of Development Economics, 5: 19-53.

Dvoskin, A.; Petri, F. (2017) "Again on the relevance of reverse capital deepening and reswitching”, Metroeconomica, 68(4): 625-659.

Dvoskin, A.; Feldman, G. (2018) “A Formal Assessment of New-Developmentalist Theory and Policy”, Brazilian Journal of Political Economy, Vol. 38 (3): 395-413.

Dvoskin, A.; Feldman, G.; Ianni, G. (2019) "New-Structuralist Exchange-Rate Policy and the Pattern of Specialization in Latin American Countries", Metroeconomica (forthcoming), DOI: 10.1111/meca. 12265

Frenkel, R.; Ros, J. (2006) "Unemployment and the Real Exchange Rate in Latin America”, World Development, 34(4): 631-646.

Garegnani, P. (1970) "Heterogeneous Capital, the Production Function and the Theory of Distribution", Review of Economic Studies, 37(3): 407-436.

Garegnani, P. (1984) "Value and distribution in the classical economists and Marx", Oxford Economic Papers, 36(2): 291-325.

Kaldor, N. (1970) “The case for regional policies”, Scottish Journal of Political Economy, 17 (3): 338-348.

Kurz, H.; Salvadori, N. (1995) Theory of Production. A Long-Period Analysis. Cambridge, Melbourne and New York: Cambridge University Press.

Marques Ribeiro, R.S.; McCombie, J.S.L.; Tadeu Lima, G. (2017) "Some unpleasant currency-devaluation arithmetic in a post Keynesian Macromodel”, Journal of Post Keynesian Economics, 40(2): $145-167$.

Panico, C. (1988) Interest and Profit in the Theories of Value and Distribution. London: Macmillan.

Pivetti, M. (1985 [1990]) "On the Monetary Explanation of Distribution". In K. Bharadwaj, \& B. Schefold (Edits.), Essays on Piero Sraffa: Critical Perspectives on the Revival of Classical Theory. London: Unwin Hymann.

Pivetti, M. (2013) "On Advanced Capitalism and the Determinants of the Change in Income Distribution: A Classical Interpretation”, in Levrero, E., Palumbo, A., Stirati, A. (Eds.) Sraffa and the Reconstruction of Economic Theory: Vol. 1, Palgrave Macmillan: 176-191.

Serrano, F.; Summa, R. (2015) "Mundell-Fleming without the LM curve: the exogenous interest rate in an open economy”, Review of Keynesian Economics, 3 (2): 248-268.

Smithin, J. (2002) "Interest parity, purchasing power parity, "risk premia” and Post Keynesian economic analysis", Journal of Post Keynesian Economics, 25(2): 219-235.

Sraffa, P. (1960) Production of Commodities by Means of Commodities. Cambridge: Cambridge University Press.

Steedman, I. (1999) "Production of Commodities by Means of Commodities and the Open Economy", Metroeconomica, 50(3): 260-276. 